\title{
Factors affecting the help-seeking behaviour of Black Asian minority ethnic (BAME) groups for mental health services in the UK: A literature review
}

\author{
Lucy Jacobs $^{1}$ and iD Panagiotis Pentaris $^{2}$ \\ ${ }^{1}$ Adult Services, London Borough of Bromley \\ ${ }^{2}$ School of Human Sciences \& institute for Lifecourse Development, University of Greenwich
}

Received 4 June 2021

Accepted for publication 10 September 2021

Published 20 September 2021

\begin{abstract}
There are numerous reports from government publications, mental health charities, the World Health Organisation and array of research articles all writing about mental health issues in relation to Black, Asian, and minority ethnic (BAME) groups. It is widely recognised that there are disparities in the treatment received by BAME individuals from mental health services. It is also commonly reported that BAME individuals are more likely to access mental health services via adverse routes - this prognosis is said to worsen in the case of Black males. This review aims to explore what factors influence BAME individuals' help-seeking behaviour for mental health services in the UK. It also explores why BAME individuals access mental health services at certain entry points, and briefly touches on the gendered perspectives of mental health. This is a systematic literature review of 16 peer-reviewed research papers from electronic databases reporting on data from UK-based studies in a thematic style. The inclusion criteria comprise studies published between 2008 and 2018, involving 18+ year old individuals with mental health issues. Boolean indicators were used with the key words 'ethnic minorities', 'help seeking', 'mental health' and 'mental illnesses' to fine-tune the search output. The help-seeking behaviours of participants in the studies are strongly determined by the values and beliefs they hold, which are deeply steeped in their culture. BAME individuals report that mental health professionals do not understand nor seek to understand their religious and cultural views on mental illnesses. Also, the impact of internalised and external stigma instigates secrecy whereby individuals hide their symptoms from professional mental health services and even from their extended family members. Culture plays a major role and impacts directly on peoples' helpseeking behaviours. Whilst individuals from BAME background would seek support from extended family members for physical illnesses, they would conceal their mental health symptoms. Adopting a culturally sensitive practice will better prepare social work professionals to engage with BAME groups and understand their needs.
\end{abstract}

Keywords: ethnic minorities, help-seeking behaviour, beliefs, stigma, service provision, acculturation, BAME

\section{Introduction}

A report by the Mental Health Foundation (2016) states that mental health problems are of a growing concern in the UK and globally, which is further compounded by the difficulty in measuring the prevalence of mental health illnesses due to lack of funding, the varying diagnostic tools, and a somewhat hidden nature of mental health illnesses.
There are no other health conditions in terms of prevalence, persistence and sheer scope of the socio-economic impact that can equate to that of mental ill health (Center for Social Justice, 2011). In 2001, The World Health Organisation (WHO) reported that one in four people will at some point in their lives experience or suffer from a mental health condition. The same report also stated that around 450 million people are already experiencing mental health issues making the 
condition one of the leading causes of poor health and disabilities globally (WHO, 2001). These numbers are concerning, but what is equally disquieting is that mental illness manifests or is represented disproportionately in different parts of the population. Statistics show that BAME individuals with mental health issues are disproportionately represented in hospitals (MIND, 2013). This is evident as African, Caribbean, and black and white mixed ethnic heritage people are three times more likely to be admitted to a mental health ward as compared to the rest of the population (Mind, 2019). These figures become even more stark when looking at the percentage of ethnic minority groups with regards to their likelihood of being sectioned under the Mental Health Act. Data from the Mental Health Act Commission (MHAC) biannual report published in 2009, show that BAME groups who are already overrepresented, appear to be disproportionately subject to supervised community treatment orders (MHAC, 2009). The detention rates for Black groups are over four times that of their Caucasian counterparts (NHS Digital, 2019).

The consequence of the above concerns is inherent in the following data: Figures from the mental health crisis resolution and home treatment (CRHT) teams in England show that BAME patients tend to be more unwell at the time of admission as compared to the white majority groups, which is congruent with data showing that BAME groups tend to seek help from mental health services at a much later stage (MIND, 2013). Hence it stands to reason why these groups are more likely to access mental health services in an adverse manner (Bhui et al., 2003; Bansal et al., 2014). Despite reports about the adverse nature of BAME individuals contact with mental health services there is a limited amount of research in this area, which limits our understanding of the true impact of mental illness on BAME groups (Mental Health Foundation, 2016).

In 2005, the Department of Health introduced the 'Delivering Race Equality' (DRE) five-year action plan. Its aim was to reform mental health services with a focus on reducing the inequalities in accessing mental health services by the BAME Communities by 2010. This followed an independent enquiry into the death of David Bennett, a 38 year-old man who died whilst being restrained in a psychiatric unit. DRE goals were established as a 12-point action plan. Notable among this was action-point 4; 'A decrease in the disproportionate rate of detention under the Mental Health Act of BAME people to psychiatric inpatient units' (DRE, 2010, p.5).

Despite the apparent robustness of this action plan, when the mental health charity MIND submitted its published findings from a year-long independent enquiry into crisis care, it found that people from BAME groups were still being treated neglectfully or coercively in the crisis care system. A report by an independent mental health task force to the NHS also concluded that the 5-year DRE programme did not yield an improvement in the experience of people from minority ethnic communities receiving mental health care (Mental Health Task Force, 2016).

The briefing by the Centre for Social Justice (CSJ) in 2011, states that evidence has shown that treatment alone of mental health illnesses would only reduce the burden of its impact by $28 \%$. However, it is worth noting that there is the gendered aspect of mental health inherent in the patriarchal system of some ethnic minority groups (Barn, 2018). The challenge could then be for social work professionals to identify the women who are not even captured in these statistics let alone seek to offer them treatment.

This lends itself to the significance of the study; to delve into the socio-cultural attributes of mental health. There is an imminent need to address the contributing causes of mental illnesses by exploring the social factors and the wider community, as social support provides a sense of belonging (CSJ, 2011). Doing this may help forge a better insight into the social factors affecting the help-seeking behaviours for mental health services of BAME groups. Although the findings in the CSJ briefing state that a record number of people are now accessing treatment and care, it claims that the process can only be genuinely successful if mental health services are fit for purpose. Interestingly, the CSJ (2011) policy briefing states that the causes of poor mental health are generally split into three domains, 'biological', 'social' and 'psychological' causes, which often interact with one another. Consequently, the versatility of social work practice means that practitioners are directly involved with individuals for interventions across all three aforementioned domains, so as earlier mentioned the outcome of this study would forge a more conclusive insight into the help seeking behaviours of BAME groups to inform methods of intervention.

\section{Methodology}

This is a systematic literature review with a thematic approach to analysing the findings (Boland, Cherry and Dickson, 2017). Petticrew and Roberts' (2008, p19) breakdown of the stages in carrying out a systematic review is used as guide:

1. Clearly define the question(s) that the review is seeking to answer.

2. Carry out a comprehensive literature search from databases relevant to the subject matter.

3. Screen the search results using clearly defined inclusion/exclusion criteria.

4. Critically appraise the emergent themes from the studies.

5. Synthesise the studies exploring heterogeneity.

6. Draw up a conclusion of the findings of the review with giving the implications and recommendations for future practice with a view to the possibility of dissemination.

This method permits the emergent themes to start speaking for themselves and allows for a theoretical dissection of the findings. Thus, the review considers critical theory as the 
theoretical framework for appraising the findings. This is because critical theory negotiates a broad range of ideologies like empowerment and anti-discrimination to explain social inequalities (Payne, 2014). The analysis further appraises the findings through the lens of Wolfersberger's (1983) theory of social role valorisation - this theory explains how society devalues people by assigning them qualities that have been classed as negative. This resonates with labelling theory, which facilitates the public dialogue about the perceptiveness of those living with a mental health diagnosis (Beckett and Taylor, 2016).

To facilitate this systematic review, electronic searches were conducted via the databases: Academic Search Premier, MEDLINE, PsycInfo, and PsycArticles. Further literature was searched for across platforms like Emerald Online, Sage Online and Social Care Online. The method of citation chaining also known as snowballing was used to search for relevant articles (Boland, Cherry and Dickson, 2017).

\subsection{Search criteria}

The initial search in the databases yielded 17,254 journal articles, using the Boolean indicator 'AND' with the key words 'ethnic minorities', 'help seeking', 'mental health' and 'mental illness'. These were systematically reduced by applying the following limiters: studies between the years 2008 and $2018(n=7,964)$, peer-reviewed and research papers $(\mathrm{n}=7,065)$, UK-based studies $(\mathrm{n}=1,464)$, empirical studies and the addition of the keyword 'spirituality' due to the prevalence of faith and religion in the articles $(n=79)$.

Moreover, seven further articles were sourced from searching the 'Social Work Online' database and the 'Google Scholar' search engine. There were three more articles found by snowballing which brought the grand total to 89 articles.

Table 1. Inclusion and exclusion criteria

\begin{tabular}{|l|l|}
\hline Inclusion criteria & Exclusion criteria \\
\hline $\begin{array}{l}\text { BAME 18+ years with } \\
\text { mental health issues }\end{array}$ & $\begin{array}{l}\text { Studies that did not recruit } \\
\text { participants of BAME } \\
\text { background and 18+ years } \\
\text { of age with mental health } \\
\text { issues }\end{array}$ \\
\hline $\begin{array}{l}\text { Studies published between } \\
\text { 2008 and 2018 }\end{array}$ & $\begin{array}{l}\text { Studies published outside of } \\
\text { the 2008-2018 time period }\end{array}$ \\
\hline $\begin{array}{l}\text { Peer-reviewed empirical } \\
\text { studies }\end{array}$ & $\begin{array}{l}\text { Non-peer-reviewed and } \\
\text { non-empirical papers }\end{array}$ \\
\hline UK-based studies & Non-UK-based studies \\
\hline
\end{tabular}

\subsection{Sifting and saturation of articles}

The 'PQRST' (Preview, Question, Read, Summarise and Test) reading tool is a structured way of reading through items, which incorporates having a 'quick overview', 'getting the gist', 'critiquing and analysing' and 'questioning' (Kiteley and Stogdon, 2014). Below is a description of how this tool was applied.

Preview: Of the 89 articles selected, the titles, sub-titles, key words, abstracts, and introductions were skim-read, to eliminate duplicates, or non-relevant papers.

Question: Identification of the research question(s) that the paper is addressing.

Read: The papers were read in more detail to check that the data drawn within the main body is still as relevant as depicted in the abstract. The were some studies that were initially identified as UK-based, but the primary data was drawn from other countries, therefore were excluded.

Summarise: Themes and sub-themes were identified and summarised.

Test: The emergent themes were tested against the research questions for possible answers.

Following these steps made it more reassuring that the final 16 articles were of a good representation to be used to in the review.

Whilst a systematic review calls for an extensive search to identify all relevant studies for the chosen topic, it is probably impossible to tell if every single study has been found because of the difficulty in trying to prove a 'negative' (Pettigrew and Roberts, 2009). It is advisable that when the same articles keep resulting from different database searches the search process must scale down (Aveyard, 2018). This was the approach used for this review.

Figure 1 depicts the sifting process more clearly, by means of the PRISMA flow diagram while applying inclusion and exclusion criteria to the search results (Table 1). The sifting and saturation process led to 16 articles for review.

\section{Findings}

Table 2 (see appendix) shows the list of the 16 papers included in this review. There were four main themes that emerged from the studies which further generated 'subthemes' according to similarity (Table 3 ). The following sections report on these in more detail. 
Figure 1: PRISMA diagram
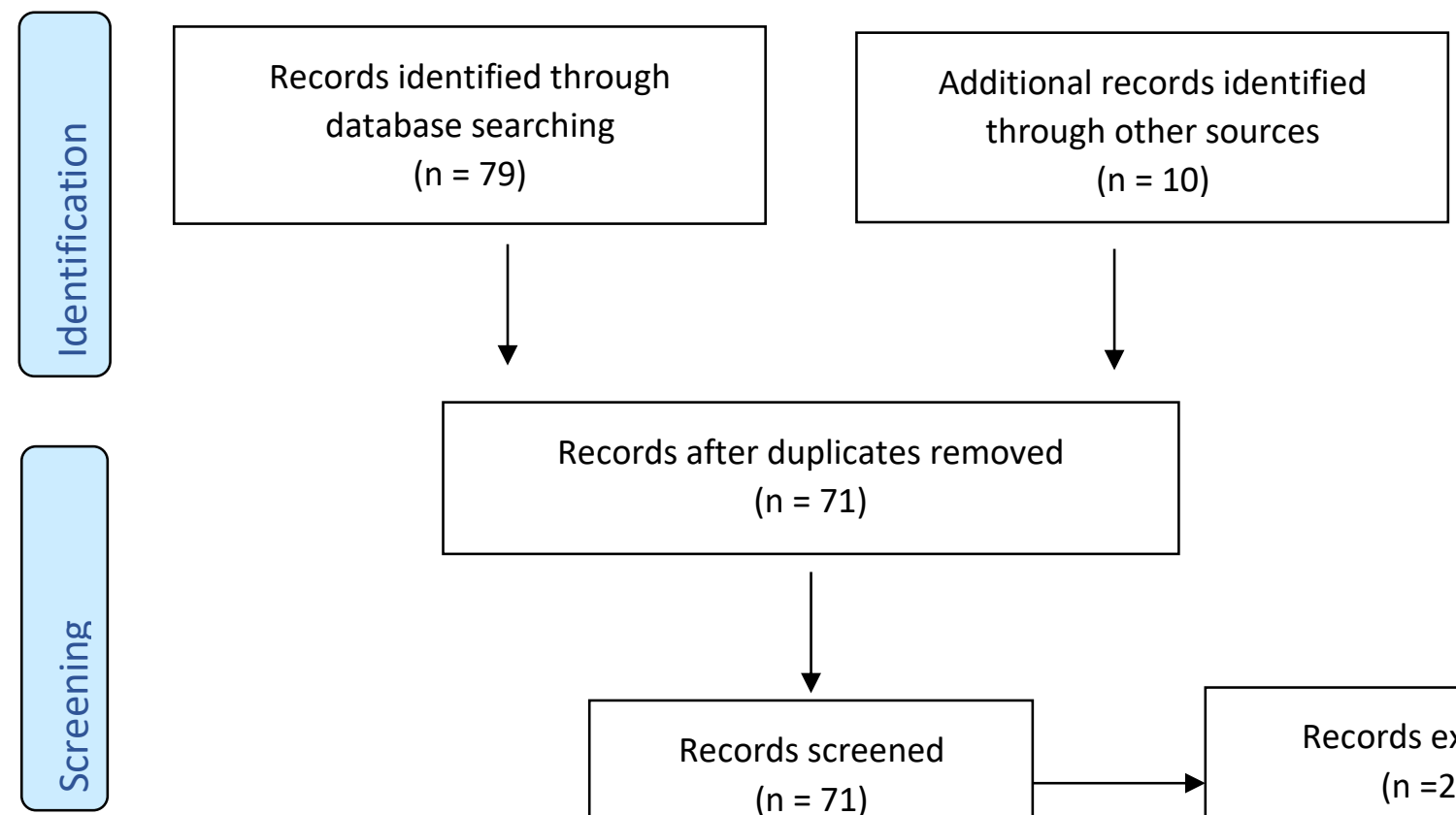

Records after duplicates removed

$$
(n=71)
$$

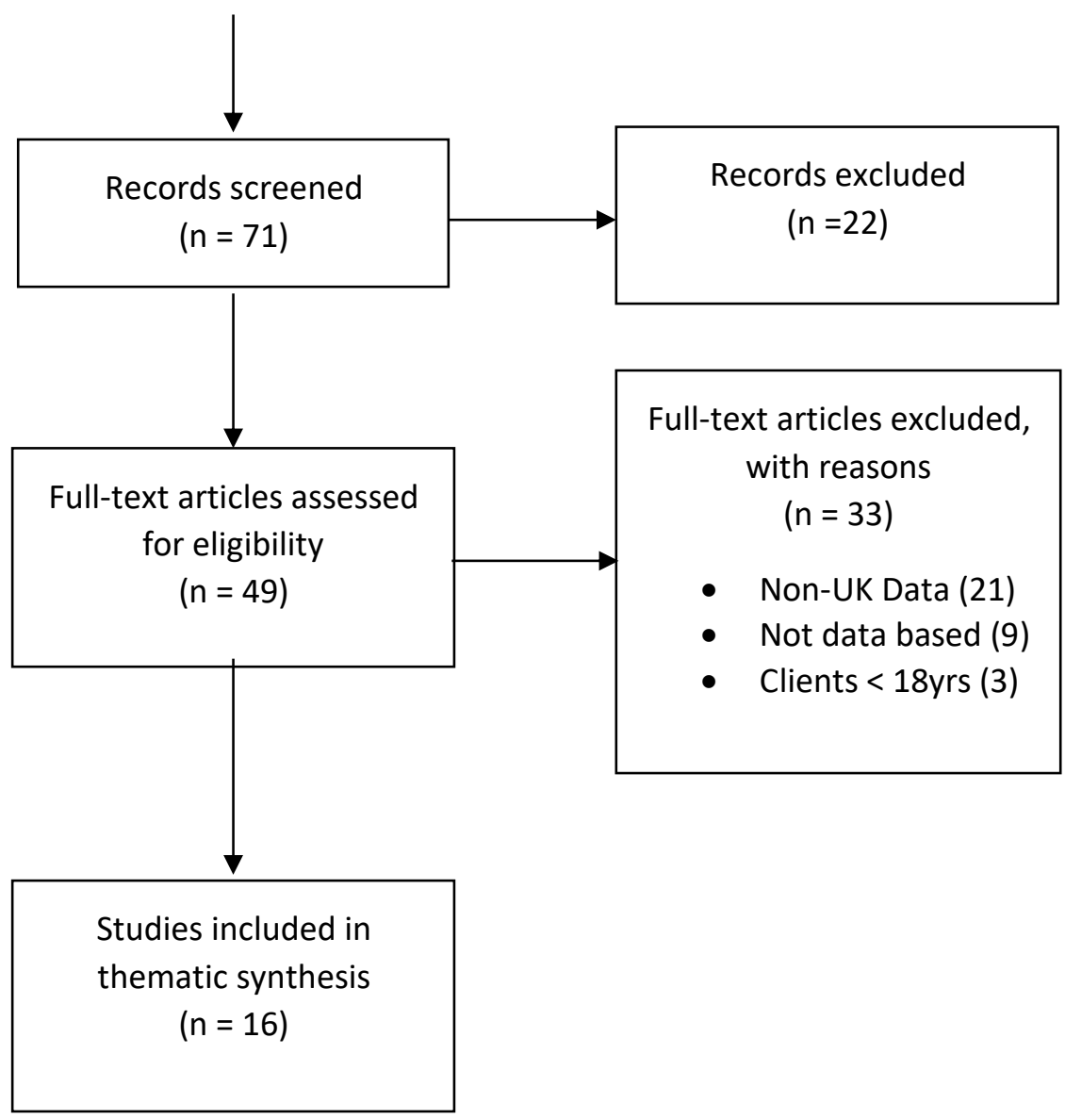

(Moher et al., 2009, p8) 
Table 3. Themes and subthemes

\begin{tabular}{|ll|}
\hline Themes Identified & Sub-themes \\
Values and beliefs & $\begin{array}{l}\text { Gender role, Self-Rating of Mental Health (SRMH), Family } \\
\text { dynamics, Cultural perception of Wellness, Variation in } \\
\text { understanding, Support network, culturally sensitive care, African } \\
\text { Christianity, Spirituality. }\end{array}$ \\
Experience of service provision & $\begin{array}{l}\text { Mistrust of services, Poor service provision, culturally sensitive } \\
\text { intervention, Comorbidities, Substance misuse, Complexity in } \\
\text { communication, Dissatisfaction with therapies. }\end{array}$ \\
Stigma & $\begin{array}{l}\text { Internal and external stigma, discrimination, status loss, social class. } \\
\text { Acculturation }\end{array}$ \\
Immigration, Language, Environment, Behaviour change, Past and \\
present experiences, social class, Poverty, newly arrived \\
communities.
\end{tabular}

\subsection{Values and beliefs}

This theme appeared predominantly across all the studies (Agius, Talwar and Zaman, 2010; Leavey, Loewenthal and King, 2017; Codjoe et al., 2012; Giebel et al., 2016). Research suggests that there is an intense connection between values and belief systems and mental health perceptiveness and help-seeking behaviours. The socio-cultural belief about mental health did not conform to the medical model of mental illness nor did it resonate with the continuum model which explores the varying degrees of mental illness.

Studies report that people felt their symptoms were as a result of 'Black magic' creating a detachment from the causality or an ambiguity in the explanation of the causes of their mental health illness (Islam, Rabiee and Singh, 2015; Rathod et al., 2010). Islam Rabiee and Singh (2015) and Rathod et al. (2010) found that people with lived experience (i.e., those at the receiving end of services) have multiple, competing, and contrasting explanatory models of illness. Help-seeking involves support from faith or spiritual healers, before seeking medical intervention. Moreover, Sisley et al. (2011) identified a gender role in mental health. This emerged in Barn (2008); he posited that underreporting of mental illnesses in Bangladeshi women may be caused by how they viewed mental illness, while there is a dearth of research into the patriarchy and the interconnectedness of race, ethnicity as well as gender in mental health issues. Prevailing religious and cultural belief systems have also been found to influence help-seeking behaviours due to the perceived dichotomy between physical and spiritual causality of mental health illnesses (Onyigbuo, Alexis-Garsee and van den Akker, 2016).

\subsection{Experiences of service provision}

The experiences of BAME groups with mental health services appear to impact on help-seeking behaviours. Participants in a study evaluating a mental health service provision in Birmingham (Rabidee and Smith, 2013) reported that mental health staff neither understood nor respected their (i.e., people with lived experience) spiritual views. However, the study highlighted the views of professionals who also felt that there needed to be a balance between respecting cultural beliefs and practices whilst being able to challenge them where appropriate.

A study of Bangladeshi women in Tower Hamlets (Barn, 2008) found that mental health professionals tended to offer these women drug-therapy rather than a non-drug counselling to mitigate their emotional needs. These interventions are often seen as the pragmatic approach to treatment due to the communication challenges, an assumption that these women do not wish to express their emotions or the perception that these women have a strong belief in drug-based intervention.

Despite the difficulties in developing an appropriate effective mental health service, a successful trial was conducted by Lovell et al. (2014) to develop a culturally sensitive psychosocial intervention for underreached communities. This was done by mass screening of patients registered with their primary care provider. Even though this was hailed as a successful trial, it did highlight the inherent weaknesses and limitations in involving the hard-to-reach individuals that were not registered with a primary care provider who would have been missed out. 


\subsection{Stigma}

Stigma in mental health can be external; like social stigma where there is discrimination and prejudice towards the person who has been labelled with a psychiatric diagnosis or internalised; where there is a perceived sense of stigma by the person with the illness creating a sense of shame (Davey, 2013). The study by Islam, Rabiee and Singh (2015) found that especially among the South Asians, the fear of social shame and stigma impacted negatively on the help-seeking behaviours.

In a study involving African-descended Christians (Mantovani, Pizzolati and Edge, 2016), those with a mental health diagnosis were found to be susceptible to a triple jeopardy with regards to stigma. This is made up of the beliefs regarding the causes of mental illness, the 'silencing' due to their ideologies of stigma and the maintenance of the stigma at the community level. As such stigma was reported to be occurring at a three-tier stratum that were both inter-connected and mutually reinforcing - comprising the 'self', the 'social' and the 'structural' strata. Internalised stigma appears to rank just as high as social sigma across both African-Caribbean and South Asian communities as put forward by Rathod et al. (2010). The tendency for families to be stigmatised as a group was explored by Knifton (2012). It was pointed out that Goffman (1963) also made the same claim that people close to an individual labelled with a mental illness also become stigmatised, especially extended family members.

Shefer et al. (2013) explored the complexity with stigma and cultural beliefs. The researchers reported their results into four 'voices' namely the critical, the medical, the traditional and the integrating voice. The critical voice was made up of the views of participants who were critical of the cultural beliefs and practices in their own communities regarding mental illness. Furthermore, when participants linked the 'self-critical' voice to families, they reported that difficulties arose when trying to conceal their illness from extended family members. According to Knifton et al. (2009), the patterns of mental health stigma vary across communities. These variations can be identified according to religious beliefs, gender, era, and age creating a heterogeneous landscape of stigma.

\subsection{Acculturation}

Onyigbuo, Alexis-Garsee and van den Akker (2016) described how Nigerian immigrants in the UK were affected by challenges in the new environment, causing low selfesteem and financial difficulties. The study went on to elaborate the aspect of behaviour change as a collaboration between both professionals and service users as an aspect of acculturation, such that behaviours need to change towards supplying and receiving relevant health care information to facilitate better mental health outcomes.

Immigration was also seen as a key factor in the difference between the experiences of asylum seekers and those with UK settled status in the research by Rabidee and Smith (2013). The study revealed that asylum seekers and refugees within the West African communities had major issues raised about the severity of some mental health challenges that were not diagnosed by GPs (i.e., general practitioners). The same study also highlighted language barriers causing problems in providing appropriate therapy like talking therapies. Acculturation does not just affect asylum seekers but also 'newly arrived' migrants as their coping techniques that had previously existed can get offset by the patterns of discrimination that BAME are more susceptible to (Sizmur and McCulloch, 2016).

Barn (2008) shed some light on the gendered aspect of acculturation on help-seeking attitudes. The study referred to the patriarchal system that South Asian women were used to in their country of origin; women had their all-female camaraderie that is consistent with the gender divide which served as their social support network. However as new migrants, they may lose this network and are confined to a new urban modernity. The study reported that language barriers, cultural disconnectedness, emotional and social isolation, and poverty were the underlying factors affecting women's mental health.

However, Mantovani, Pizzolati and Edge (2016) offered a slightly different view on acculturation. There was a debate as to whether there was a difference in the attitudes towards mental health among the Black people born in the UK versus those who migrated from Africa and the Caribbean. Some participants felt that acculturation brought about a change in the perception of mental illness, whilst others were nonplussed by the lack of change over time.

\section{Discussion}

Whilst there is no definitive and agreed definition of the word 'society', sociologists would concede that it is a large unit that consists of self-perpetuating processes, has a common culture, occupies a bounded territory, and encompasses a population that alludes to constituting a distinct entity (Roberts, 2009). The culture of a society is a way of life made up of ideas and habits learnt, shared, and passed down the generations and, to a large extent, dictates how its members think, feel, act, even defining their outlook on life (Haralambos et al., 2013). That said, it would not be possible to analyse the behaviours of BAME groups without exploring the impact of society and the cultures that are at play therein.

The emergent themes from the reviewed studies demonstrate that there is a belief system in place which posits that mental health issues are of a spiritual nature. In some cases, regarded as out of the hands of the sufferer and in other cases the sufferers are seen to have played a part bringing it upon themselves in form of a weakness or lack of faith (Sisley et al., 2011; Shefar et al., 2012). Consequently, there were strong links to stigma. The three-tier stratum of stigma exemplifies the concept of external stigma in society which is 
consistent with Roberts' (2009) definition of society as comprising a self-perpetuating process.

In the three-tier stratum, stigma is maintained at a community level (Mantovani, Pizzolati and Edge, 2016). This phenomenon can be explained with labelling theory. Sociologist Howard Becker (1963) argued that it is the dominant social groups that assign labels to specific parts of the population; subsequently the labelled person becomes a deviant. Therefore, when people with mental illnesses are labelled as deviant, it overrides any other status that they had acquired or aspire to achieve. What some of the reviewed studies revealed is that where a family member whose cultural beliefs denotes that anyone suffering with mental health is a deviant, the family would seek to hide the 'deviant' away from view. Study participants also stated that they must keep their condition a secret even from extended family members. This is consistent with Merton's (1948) theory of the self-fulfilling prophecy, where the individuals have themselves accepted this deviant role and would rather maintain the secrecy as is expected of them than seek help. This is further compounded by the racial stigma that comes with being part of the BAME community as hypothesized by Erving Goffman (1963), who opined that people are stigmatised on three levels: character traits, physical traits, and group identity stigma. That said, people from a BAME background would consequently have a double stigma to contend with.

Yuill and Gibson (2011) put forward a psychosocial approach to analyse this emotional experience of living in a society with a relative inequality. They posit that the negative emotions experienced by ethnic minorities result in bad health, seeing as previous theories of genetic cultural causalities and the notion that biological factors predisposing people from ethnic groups to poor health have been debunked. One theory that originally began as the principle of 'normalisation' in learning disabilities services which has since been applied throughout social work is 'Social Role Valorisation' (SRV) (Wolfensberger, 1993 cited in Caruso and Osburn, 2011). He defined SRV as the enablement, formation, augmentation, maintenance of socially valued roles for people who are at risk of being devalued by others by using culturally valued means. People who have an impairment of the mind are classed as holding a devalued role in society, therefore susceptible to be placed in settings and/or allocated activities that valued people in society do not want, and they are likely to be unwelcomed into societal participation (Wolfensberger, 2000).

The role of the client was analysed from an SRV perspective by Wolfensberger and Thomas (1994). They postulated that in contemporary societies everyone is a client in some regard whether to an attorney, a hair-dresser, an employer, educational or social service agency. However, being a client of a high-powered solicitor or expensive hairdresser would be classed as a valued client role as opposed to a client of a welfare service, and mostly devalued is one in receipt of human services for life otherwise referred to as occupying a 'career client role'. Wolfensberger and Thomas also point out that there is a historic universality across cultures in the way devalued people have been assigned socially negative roles, some include the role of menace or object of dread, the object of pity, the burden of charity, the 'sick' or 'diseased', the dead or dying and many more that are built into the schema or the construct of social roles.

The participants in the reviewed studies all alluded to seeing themselves as afflicted in the same way their social networks, ranging from family to wider community, labelled them in these roles. There appeared to be a sense of learned helplessness (Peterson, Maier and Seligman, 1993), although this review has not delved into that concept.

The concept of devaluation also resonates with the precepts of critical theory. Critical theorists argue that it is the structure of society that causes social problems based on the cultural assumptions by the dominant group impressed upon the subordinate groups, such that the individual and psychological aspects of peoples' make-up are a less important determinant of their issues (Payne, 2014). Critical theorists challenge the assumption that just because there is the presence of a set social order that one must accept it. Therefore, it encourages people to raise questions about practices that are part of this presumed order (Adams, Dominelli and Payne, 2002). An example was given where people with disabilities complain that social workers assess them as living in a society with an impairment that makes them sub-human, rather than acknowledging the fact that most of their disabilities are exacerbated by a society that is built to suit able-bodied persons (Adams, Dominelli and Payne, 2002).

Although critical theory is not without its critiques, it focuses on the power emanating from practitioners within statutory services, whilst overlooking the power wielded in religious oppression and human rights abuses and so on (Payne, 2014). Nevertheless, it is important to note that there are certain laws in place that organisations must abide by. In England and Wales, the Equality Act 2010, covers nine protected personal characteristics, two of which are disability (physical and mental) and race. It prohibits unlawful behaviours like discrimination and harassment and gives people the right to challenge these prohibited behaviours from organisations like employers and service providers.

It is evident in this review that there is a strong link between culture and religion, where cultural beliefs often determine what actions or lack of actions are taken by BAME individuals vis-à-vis help-seeking behaviors. If certain cultural beliefs have made individuals accept a deviant role, it begs the question how would they seek to challenge what the Equality Act 2010 would class as prohibited behaviours? Studies demonstrate that clients' experiences of mental health services impact on their help-seeking behaviors due to lack of professional recognition of their values and belief systems.

Moving onto the concept of acculturation, participants in the reviewed literature are mainly made up of individuals who have either migrated to the UK or are second to thirdgeneration descendants of migrants to the UK. Therefore, it 
stands to reason that acculturation was among the themes that emerged from the studies. Although the precepts of SRV and critical theory encourage a move away from the unhelpful structural and dominant cultural hegemony to an improved individualised cultural fit to eradicate social inequalities by raising conscientiousness, how do they then accommodate the concept of acculturation? A meta-analysis (Sun et al., 2016) in America posited that even though acculturation and enculturation is generally split into the framework of unidimensional acculturation, bidimensional acculturation and bidimensional enculturation, empirical studies have found that individuals can hold more than two cultural orientations to different degrees with varying levels of correlation between them. This may lead to a certain degree of complexity with the way the theories are applied as different degrees of acculturation may then mean individuals are experiencing structural oppression in a non-linear, disjointed form. This is because acculturation and enculturation are multifaceted, complex processes that contain a range of salient domains like behaviours, attitudes values and sense of identity which is further complicated by the fact that researchers are yet to reach a consensus regarding the exact number of domains (Sun et al., 2016).

\section{Conclusion}

To answer the initial question - what factors influence BAME people's decision-making processes to access mental health services at certain stages - we are taken back to Nobles' (1985) model of culture (cited in Livingston et al., 2008). Nobles' study is postulating that there is not necessarily a deliberate attempt to avoid accessing services rather it was the narrative behind the self-reporting that defined the early stages of distress as not requiring help.

The fact that there is a disproportionate ratio of BAME, especially men accessing the mental health system via adverse means, begs the question what prevented them from accessing services earlier. A key factor that links anyone identifying themselves as a member of the BAME background is that they are a person living in a place outside of their ethnic origin, as such bringing a diverse mix of cultures into the geographical area. Nobles et al. $(2014$, p.8) posit that culture is an 'invisible medium that encompasses all human existence', where cultural manifestations are demonstrated by values, language, rituals, symbols and customs.

When it comes to physical health, families from the BAME groups preferred to seek support, solace, and respite from their extended family members rather than accessing palliative care services for their children (Pentaris et al., 2018). This is in stark contrast to mental health, where people tend to hide their symptoms of mental health distress from extended family members (Shefar et al., 2012).
To understand and effectively address the intricate nature of BAME groups, there needs to be an exploration into the intersectionality of the many facets that make up identity (Pentaris, 2019). Taking into consideration the results of this review, culture plays a major role in driving those factors, acting as a barrier to accessing help. It also provides an answer to what influences help-seeking behaviours at different stages of intervention. This does not necessarily mean that people with lived experience disapprove of mental health services; rather, they cannot relate to it in the way it is delivered, thus calling for a more culturally sensitive practice.

\section{Recommendations for practice}

The following two recommendations aim at encouraging a progression from the on-going narratives: 'BAME access to mental health services are disproportionately adverse', 'BAME groups are hard to reach and engage', to a narrative that depicts an amelioration of these notions.

- A move towards a more diverse service provision that is indicative of the psychosocial make-up of the UK population.

- A move towards promoting research geared towards analysing data that is ethnically relevant which could feed into evidence and research-based practice. This could be done in conjunction with increasing health literacy.

The World Health Organisation (2018) has elucidated the concept of health literacy by defining it as the cognitive and social skills that determines the incentive and ability of people to gain access to, comprehend and utilise information in ways that would promote and maintain good health. The report by the People and Communities Board to the NHS England (2018) states: "the strongest correlation to ill health is "Health Literacy", in that it surpasses educational attainment, deprivation, age or ethnic background'. If professionals take on the role of 'educator' to those receiving services, then they can seek to bridge the gap or possibly overcome the perception of the cultural divide between BAME groups and service provision. It will also be beneficial where service users are grappling with the different dimensions of acculturation. This will enable people with lived experience to improve their health literacy and efficiently access services regardless of where they find themselves. In addition, the development a culturally sensitive practice that is evidence-based will better prepare professionals to engage with people with lived experience from diverse backgrounds. This, in turn, could change the narrative of BAME groups' experiences of mental health services to a more positive outlook following an improved cultural humility of mental health professionals. Finally, the benefits of research cannot be overemphasized and its importance in feeding into future research-informed 
practice. Further studies steeped in cultural sensitivity with empirical evidence drawn from ethnic minorities, with a clear distinction between the domains or levels of cultures that identifies religion/spirituality as a manifestation rather than as a synonym, would add to our current knowledge and understanding in this area. Renewed understanding of the needs and experiences of BAME individuals can improve professional practice, alleviate the cultural barriers, and may even significantly improve the well-being and help-seeking behaviours of BAME groups.

\section{Limitations}

The conclusion from this review is not without limitations. The sample sizes in the reviewed articles are modest and, thus, difficult to generalise. Furthermore, this review was conducted in the space of select databases, for accessibility reasons, as well as limited itself to a ten-year period and UKbased studies. Expanding the inclusion criteria might allow for a more thorough and fuller review of current empirical evidence, while the appraisal of non-UK-based studies can allow for cross-country explorations that can add to our knowledge of diverse cultures and populations that are not the dominant in the UK. Finally, a key area that emerged from the reviewed papers was the 'gender perspective'. Whilst this was touched upon briefly in this review, it is an aspect that would benefit from future research.

\section{References}

Adams, R., Dominelli, L. and Payne, M. (2002) Critical practice in social work. Basingstoke: Palgrave.

Agius, M., Talwar, A. and Zaman, R. (2010) 'Issues regarding the delivery of early intervention for psychosis services to the South Asian population in England', European Psychiatry, 23(S2), pp.S99-S99.

Aveyard, H. (2018) Doing a literature review in health and social care. $4^{\text {th }}$ ed. Milton Keynes: Open University Press.

Bansal, N., Bhopal, R., Netto, G., Lyons, D., Steiner, M. and Sashidharan, S. (2014) 'Disparate patterns of hospitalisation reflect unmet needs and persistent ethnic inequalities in mental health care: the Scottish health and ethnicity linkage study', Ethnicity \& Health, 19(2), pp.217-239.

Barn, R. (2008) 'Ethnicity, Gender and Mental Health: Social Worker Perspectives', International Journal of Social Psychiatry, 54(1), pp.69-82.

Becker, H. (1963) Outsiders. New York: The Free Press.

Beckett, C. and Taylor, H. (2016) Human growth and development. London: SAGE.
Bhui, K., Stansfeld, S., Hull, S., Priebe, S., Mole, F. and Feder, G. (2003) 'Ethnic variations in pathways to and use of specialist mental health services in the UK', British Journal of Psychiatry, 182(2), pp.105-116.

Boland, A., Cherry, M. and Dickson, R. (2017) Doing a systematic review. $2^{\text {nd }}$ ed. London, UK: SAGE.

Caruso, G. and Osburn, J. (2011) 'The Origins of "Best Practices" in the Principle of Normalization and Social Role Valorization', Journal of Policy and Practice in Intellectual Disabilities, 8(3), pp.191-196.

Centre for Social Justice (2011) Mental health: poverty, ethnicity and family breakdown. [online] London. Available

at: https://www.centreforsocialjustice.org.uk/wpcontent/uploads/2011/02/MentalHealthInterimReport.pdf [Accessed 14 May 2021].

Codjoe, L., Byrne, M., Lister, M., McGuire, P. and Valmaggia, L. (2012) 'Exploring perceptions of "Wellness" in Black ethnic minority individuals at risk of developing psychosis', Behavioural and Cognitive Psychotherapy, 41(2), pp.144-161.

Davey, G. (2013) Mental health \& stigma. Available at: https://www.psychologytoday.com/us/blog/why-weworry/201308/mental-health-stigma [Accessed 14 May 2021].

DRE (2010) Race Equality Action Plan: a five year review. Delivering race equality in mental health care. London: Department of Health (DH) - Mental Health Division. Available http://www.hsconsultancy.org.uk/system/resources/1/race -equality-action-plan-a-five-year-review.pdf?1302161027 [Accessed 14 May 2021].

Giebel, C., Challis, D., Worden, A., Jolley, D., Bhui, K., Lambat, A. and Purandare, N. (2016) 'Perceptions of selfdefined memory problems vary in south Asian minority older people who consult a GP and those who do not: a mixed-method pilot study', International Journal of Geriatric Psychiatry, 31(4), pp.375-383.

Goffman, E. (1963) Stigma. London: penguin Books.

Haralambos, M., Holborn, M., Chapman, S. and Moore, S. (2013) Sociology Themes and Perspectives. $8^{\text {th }}$ ed. London, UK: Collins.

Islam, Z., Rabiee, F. and Singh, S. (2015) 'Black and Minority Ethnic Groups' Perception and Experience of Early Intervention in Psychosis Services in the United Kingdom', Journal of Cross-Cultural Psychology, 46(5), pp.737-753.

Kiteley, R. and Stogdon, C. (2014) Literature reviews in social work. Los Angeles, CA: SAGE.

Knifton, L. (2012) 'Understanding and addressing the stigma of mental illness with ethnic minority 
communities', Health Sociology Review, 21(3), pp.287298.

Knifton, L., Gervais, M., Newbigging, K., Mirza, N., Quinn, N., Wilson, N. and Hunkins-Hutchison, E. (2009) 'Community conversation: addressing mental health stigma with ethnic minority communities', Social Psychiatry and Psychiatric Epidemiology, 45(4), pp.497504.

Leavey, G., Loewenthal, K. and King, M. (2017) 'Pastoral care of mental illness and the accommodation of African Christian beliefs and practices by UK clergy', Transcultural Psychiatry, 54(1), pp.86-106.

Livingston, J., Holley, J., Eaton, S., Cliette, G., Savoy, M. and Smith, N. (2008) 'Cultural competence in mental health practice', Best Practices in Mental Health, 14(2), pp.1-14.

Lovell, K., Lamb, J., Gask, L., Bower, P., Waheed, W., ChewGraham, C., Lamb, J., Aseem, S., Beatty, S., Burroughs, H., Clarke, P., Dowrick, A., Edwards, S., Gabbay, M., Lloyd-Williams, M. and Dowrick, C. (2014) 'Development and evaluation of culturally sensitive psychosocial interventions for under-served people in primary care', BMC Psychiatry, 14(1), pp.1-16.

Mantovani, N., Pizzolati, M. and Edge, D. (2016) 'Exploring the relationship between stigma and help-seeking for mental illness in African-descended faith communities in the UK', Health Expectations, 20(3), pp.373-384.

Mental Health Foundation (2016) Fundamental Facts About Mental Health $2016 . \quad$ Available at: https://www.mentalhealth.org.uk/sites/default/files/funda mental-facts-about-mental-health-2016.pdf [Accessed 2 June 2021].

Mental Health Task Force (2016) The five-year forward view for mental health. NHS England. Available at: https://www.england.nhs.uk/wpcontent/uploads/2016/02/Mental-Health-TaskforceFYFV-final.pdf [Accessed 14 May 2021].

Merton, R. (1948) 'The self-fulfilling prophecy', The Antioch Review, 8(2), pp.193-210.

MIND (2013) Mental health crisis care: commissioning excellence for Black and minority ethnic groups. Available at: $\quad$ https://www.mind.org.uk/media/494422/bmecommissioning-excellence-briefing.pdf [Accessed 14 May 2021].

Mind (2019) Disability discrimination: a general guide on how you are protected from discrimination under the Equality Act and what your rights are. Applies to England and Wales. Available at: https://www.mind.org.uk/mediaa/3123/disability-discrimination-2019.pdf [Accessed 3 September 2021].

Moher, D. (2009) 'Preferred Reporting Items for Systematic Reviews and Meta-Analyses: The PRISMA Statement', Annals of Internal Medicine, 151(4), pp.9-17.
NHS England (2018) Enabling people to make informed health decisions. Available at: https://www.england.nhs.uk/ourwork/patientparticipation/health-decisions [Accessed 14 May 2021].

NHS Digital (2019) Mental health act statistics, annual figures. England, 2018-2019. Available at: https://digital.nhs.uk/data-andinformation/publications/statistical/mental-health-actstatistics-annual-figures/2018-19-annual-figures [Accessed 14 May 2021].

Nobles, W., Goddar, D., Haggins, K., Rett-Mariscal, W. and Williams-Flournoy, D. (2014) Redefining the definition of an African American community-defined practice. California Reducing Disparities Report. California: California Institute for Behavioral Health Solutions. Available at: https://www.cibhs.org/sites/main/files/fileattachments/african_american_communitydefined_practice_paper_0.pdf [Accessed 14 May 2021].

Onyigbuo, C., Alexis-Garsee, C. and van den Akker, O. (2016) 'An exploration of health-seeking behaviours among Nigerian Christians in the UK: towards enhanced health services utilisation', Mental Health, Religion \& Culture, 19(3), pp.255-267.

Payne, M. (2014) Modern social work theory. Hampshire: Palgrave Macmillan.

Pentaris, P. (2019) 'Religion, belief, and spirituality in health care' in Gehlert, S. and Browne, T. (eds.) Handbook of health social work. New York, NY: John Wiley \& Sons, pp.279-301.

Pentaris, P., Papadatou, D., Jones, A. and Hosang, G. (2018) 'Palliative care professional's perceptions of barriers and challenges to accessing children's hospice and palliative care services in South East London: a preliminary study', Death Studies, 42(10), pp.649-657.

Peterson, C., Maier, S. and Seligman, M. (1993) Learned helplessness. New York, NY: Oxford University Press.

Petticrew, M. and Roberts, H. (2008) Systematic reviews in the social sciences. Malden, USA: Blackwell Publishing.

Rabidee, F. and Smith, P. (2013) 'Being understood, being respected: an evaluation of mental health service provision from service providers and users' perspectives in Birmingham, UK', International Journal of Mental Health Promotion, 15(3), pp.162-177.

Rathod, S., Kingdon, D., Phiri, P. and Gobbi, M. (2010) 'Developing culturally sensitive cognitive behaviour therapy for psychosis for ethnic minority patients by exploration and incorporation of service users' and health professionals' views and opinions', Behavioural and Cognitive Psychotherapy, 38(5), pp.511-533.

Roberts, K. (2009) Key concepts in sociology. New York, NY: Palgrave Macmillan. 
Shefer, G., Rose, D., Nellums, L., Thornicroft, G., Henderson, C. and Evans-Lacko, S. (2013) "Our community is the worst': The influence of cultural beliefs on stigma, relationships with family and help-seeking in three ethnic communities in London", International Journal of Social Psychiatry, 59(6), pp.535-544.

Sisley, E., Hutton, J., Louise Goodbody, C. and Brown, J. (2011) 'An interpretative phenomenological analysis of African Caribbean women's experiences and management of emotional distress', Health \& Social Care in the Community, 19(4), pp.392-402.

Sizmur, S. and McCulloch, A. (2016) 'Differences in treatment approach between ethnic groups', Mental Health Review Journal, 21(2), pp.73-84.

Sun, S., Hoyt, W., Brockberg, D., Lam, J. and Tiwari, D. (2016) 'Acculturation and enculturation as predictors of psychological help-seeking attitudes (HSAs) among racial and ethnic minorities: a meta-analytic investigation', Journal of Counseling Psychology, 63(6), pp.617-632.

The Mental Health Act Commission (2009) Coercion and consent monitoring the Mental Health Act 2007-2009. 13. London: The Stationery Office, pp.112-113. Available at: https://www.cqc.org.uk/sites/default/files/documents/mha c biennial_report 0709 final.pdf [Accessed 2 June 2021].

Wolfensberger, W. and Thomas, S. (1994) 'An analysis of the client role from a Social Role Valorization perspective. SRV-VRS', The International Social Role Valorization Journal, 1, pp.3-7.

Wolfensberger, W. (2000) 'A brief overview of Social Role Valorization', Mental Retardation, 38(2), pp.105-123.

World Health Organisation (2018) Track 2: Health literacy and health behaviour. Available at: http://www.who.int/healthpromotion/conferences/7gchp/t rack2/en [Accessed 14 May 2021].

Yuill, C. and Gibson, A. (2011) Sociology for social work. Los Angeles, CA: SAGE. 


\section{(Year of Publication)}

\begin{tabular}{|c|c|c|c|}
\hline $\begin{array}{r}\text { Nadia Mantovani, Micol } \\
\text { Pizzolati and Dawn } \\
\text { Edge } \\
\text { (2016) }\end{array}$ & $\begin{array}{l}\text { Exploring the relationship between stigma } \\
\text { and help-seeking for mental illness in } \\
\text { African-descended faith communities in } \\
\text { the UK. } \\
\text { Sample Size } 26\end{array}$ & $\begin{array}{l}\text { Building on the evidence that faith- } \\
\text { based organizations (FBOs) can aid } \\
\text { the development of effective public } \\
\text { health strategies }\end{array}$ & $\begin{array}{l}\text { The conceptualization of mental illness as a moral } \\
\text { failing or weakness was considered problematic in } \\
\text { terms of help-seeking because it did not command } \\
\text { the same attention or level of empathic } \\
\text { understanding as physical illnesses. }\end{array}$ \\
\hline $\begin{array}{r}\text { Emma J. Sisley, Jane M. } \\
\text { Hutton, C. Louise } \\
\text { Goodbody D and June } \\
\text { S.L. Brown } \\
(2010)\end{array}$ & $\begin{array}{l}\text { An interpretative phenomenological } \\
\text { analysis of African Caribbean women's } \\
\text { experiences and management of emotional } \\
\text { distress. } \\
\text { Sample Size } 9\end{array}$ & $\begin{array}{l}\text { An exploration of individual } \\
\text { explanatory models of experiences } \\
\text { of distress, coping and help-seeking } \\
\text { choices, with a view to improving } \\
\text { cultural relevance of services. }\end{array}$ & $\begin{array}{l}\text { African Caribbean women's coping and help- } \\
\text { seeking, in response to distress, is complex and } \\
\text { subject to a broad range of interwoven influences. }\end{array}$ \\
\hline $\begin{array}{r}\text { Fatemeh Rabidee and } \\
\text { Paula Smith } \\
\\
\text { (2013) }\end{array}$ & $\begin{array}{l}\text { Being understood, being respected: an } \\
\text { evaluation of mental health service } \\
\text { provision from service providers and users' } \\
\text { perspectives in Birmingham, UK } \\
\text { Sample Size } 97\end{array}$ & $\begin{array}{l}\text { An exploration of service } \\
\text { accessibility, cultural } \\
\text { appropriateness, in meeting needs, } \\
\text { the impact of racism, discrimination, } \\
\text { culture, religion, and funding in care } \\
\text { provision. }\end{array}$ & $\begin{array}{l}\text { Lack of information and inappropriate responses } \\
\text { by front-line professionals mean that black people } \\
\text { often pursue quite torturous paths to obtain the } \\
\text { help they need or give up altogether } \\
\text { Minority status is a risk factor for increased rates } \\
\text { of mental illness. }\end{array}$ \\
\hline $\begin{array}{r}\text { Shanaya Rathod, David } \\
\text { Kingdon, Peter Phiri } \\
\text { and Mary Gobbi } \\
(2010)\end{array}$ & $\begin{array}{l}\text { Developing Culturally Sensitive Cognitive } \\
\text { Behaviour Therapy for Psychosis for } \\
\text { Ethnic Minority Patients by Exploration } \\
\text { and Incorporation of Service Users' and } \\
\text { Health Professionals' Views and Opinions } \\
\text { Sample Size } 114\end{array}$ & $\begin{array}{l}\text { To produce a culturally sensitive } \\
\text { adaption of an existing CBT manual } \\
\text { for therapists working with patients } \\
\text { with psychosis from specified ethnic } \\
\text { minority communities. }\end{array}$ & $\begin{array}{l}\text { Participants reported a common practice of } \\
\text { seeking help from faith healers. Fear of services, } \\
\text { mistrust and lack of confidence in the system are } \\
\text { other factors that were highlighted. These are } \\
\text { influenced by "shame" to the community, family } \\
\text { and to the individual. } \\
\text { Recommendations of remedies or advice of elders } \\
\text { or Imams is preferred to services. }\end{array}$ \\
\hline $\begin{array}{r}\text { Mark Agius, A. Talwar, } \\
\text { S. Murphy \& Rashid } \\
\text { Zaman } \\
\text { (2010) }\end{array}$ & $\begin{array}{l}\text { Issues Regarding the Delivery of Early } \\
\text { Intervention Psychiatric Services to The } \\
\text { South Asian Population in England. } \\
\text { Sample Size } 75\end{array}$ & $\begin{array}{l}\text { The aim of this retrospective study } \\
\text { is to gain a better understanding of } \\
\text { how well South Asian patients } \\
\text { engage with standard psycho-social } \\
\text { interventions. }\end{array}$ & $\begin{array}{l}\text { Language barriers and a lack of knowledge about } \\
\text { Asian culture and family dynamics may explain } \\
\text { why such patients engage poorly with current } \\
\text { services. }\end{array}$ \\
\hline
\end{tabular}


Steve Sizmur and Andrew Mccullogh

ethnic groups

Sample Size 13,787

Guy Shefer, Diana Rose, Laura Nellums, Graham Thornicroft, Claire Henderson, Sara

Evans-Lacko

(2013)

Gerard Leavey, Kate Loewenthal, Michael

King
'Our community is the worst': The influence of cultural beliefs on stigma, relationships with family and help-seeking in three ethnic communities in London.

\section{Sample Size 103}

Pastoral care of mental illness and the accommodation of African Christian beliefs and practices by UK clergy.

\section{Sample Size 32}

To analyse survey variables describing treatments offered to respondents for evidence of differential access or treatment experiences associated with ethnicity.

To analyse how beliefs of predominant BAME influence experiences of stigma and relationships with family for individuals with mental illness in these communities.

This study aimed to examine the problems of mental health pastoral care faced by clergy working in inner-city multi-ethnic communities
There are issues with stigma and views about the aetiology of mental illness.

Consanguineous marriages and could provide interesting information on the genetic aspects of psychosis.

Respondents in most minority groups were more likely to be on the care programme approach (CPA) to provision than white British respondents and less likely to report receiving psychological treatments.

Unmet need for psychological treatment was relatively high in certain Asian groups.

Medication use was consistently high across respondents, but differences by ethnic background were evident.

Cultural beliefs influence both relationships with family and help-seeking. So, it must be considered in the development of anti-stigma interventions and when engaging communities around mental health.

A dissonance between clergy's and the Laity's explanations of emotional and psychiatric distress. While clergy may not wholly abandon supernatural explanations of mental illness, they tend to downplay such phenomena.

White mainstream Christian clergy appear to lack the confidence and knowledge to provide culturally sensitive care. Clergy may be unable and/or unwilling to offer the assessment and treatment that the laity from African Christian backgrounds need or want. 


\section{(Year of Publication)}

Karina Lovell, et.al Development and evaluation of

Zoebia Islam, Fatemeh Rabiee, and Swaran P. Singh

\section{Sample Size 66}

Ravinder Barn Ethnicity, Gender and Mental

$$
\text { Sample Size } 84
$$

Chineme Christian Onyigbuo, Camille Alexis-Garsee and Olga van den Akker

(2016) culturally sensitive psychosocial interventions for under-served people in primary care.

Sample Size 57

Black and Minority Ethnic Groups' Perception and Experience of Early Intervention (EI) in Psychosis

An exploration of health-seeking behaviours among Nigerian

Christians in the UK: towards enhanced health services utilisation

\section{Sample Size 10}

To develop and evaluate an, acceptable and culturally sensitive psychosocial intervention for older people, and people from ethnic minority communities.

An examination of cultural appropriateness,

accessibility, and acceptability of the Early

Intervention (EI) for Psychosis Services with a view

to improving the experience of care and outcomes for

BAME patients

To study professional perspectives to enhance understanding of the interconnections of ethnicity, gender, social class and mental health, to promote improved policy, provision and practice.

To explore the responses to symptoms/illnesses in relation to healthcare utilisation among Nigerian

Christians living in a diaspora
The intervention does show preliminary evidence of effectiveness in people who do engage, although clearly major problems remain in terms of encouraging higher rates of recruitment to ensure those benefits have sufficient reach into population in need.

Service users and carers have multiple, competing, and contrasting explanatory models of illness. Help-seeking involves support from faith/spiritual healers, before seeking medical intervention.

EI clinicians perceive that help-

seeking from faith institutions in Asian service users might lead to treatment delays.

Social work practitioners believed that service provision for Bangladeshi women was fragmented, and poorly conceptualised and coordinated.

Voluntary sector remained at the vanguard of innovative practice initiatives but were disadvantaged by scarce resources, and lack of adequate consultation and partnerships with the statutory sector.

Four global themes resulted from the analytic process: Immigration challenges, Barriers to healthcare, Facilitators to healthcare, and Acculturation.

These themes form the basis of the discussions on the health-seeking experiences of Nigerian Christians living in the UK; and potential determinants of seeking medical help during illness. 
Lee Knifton, Mhairi

Gervais, Karen

Newbigging, Nuzhat

Mirza, Neil Quinn, Neil

Wilson, Evette Hunkins-

Hutchison

(2009)

Mischa Gwaspari, Sanita

Hochhauser and Matt

Bruce

(2011)

\section{Sample Size 79}

Clarissa Giebel, David Challis, Angela Worden, David Jolley, Kamaldeep

Singh Bhui, Ahmed

Lambat and Nitin Purandare.

(2015)

Louisa Codjoe, Majella Byrne, Matthew Lister, Philip McGuire, Lucia Valmaggia

(2012)
Community conversation:

addressing mental health stigma

with ethnic minority communities.

Sample Size 257

Unmet needs and antisocial

personality disorder among Black

African and Caribbean service user

with severe mental illness

Perceptions of self-defined memory problems vary in south

Asian minority older people who

consult a GP and those who do not:

a mixed-method pilot study.

Sample Size 33

Exploring Perceptions of

"Wellness" in Black Ethnic

Minority Individuals at Risk of

Developing Psychosis.

Sample Size 20
Evaluate the acceptability and practicability of a community development workshop programme, explore attitudes towards mental health problems amongst the three target communities in the study.

To investigate unmet needs of Black African and Caribbean Heritage patients with and without a

concurrent diagnosis of antisocial personality disorder.

To investigate how South Asians with self-defined memory problems, with and without GP consultation construe the symptoms, causes, consequences and treatment of the condition.

This study explored perceptions of wellness in Black African and Black Caribbean individuals with an AtRisk Mental State (ARMS) for psychosis.
BAME communities have not been reached effectively by national anti-stigma messages.

Community development workshops involving dialogue and engagement, might offer more promise than national campaigns alone in reducing the significant levels of stigma that exist within communities.

Males from Black African and Caribbean Heritage with comorbid Anti-Social

Personality Disorder more unmet needs. They were more susceptible to substance abuse problems, showed poorer academic achievement from a younger age and were more likely to have been unemployed prior to their admission.

Perceptions of dementia varied by GP consultation for memory problems.

A greater proportion of older adults without a consultation considered memory problems to be given by God, saw acceptance of fate as an alternative treatment and did not identify medical support as appropriate.

Although tentative, results suggest that differences between factors indicate that there may be perceptions of wellness specific to the ARMS Black African and Caribbean community.

These seemingly culturally specific perceptions of wellness are distinct from the medical view of wellness promoted within early detection services. It is possible that these differences may impact upon engagement with early detection services. 